\title{
Proactive Customer Relationship Management In E-Commerce
}

\author{
Freimut Bodendorf (E-mail: freimut.bodendorf@wiso.uni-erlangen.de), University of Erlangen-Nuremberg, Germany \\ Susanne Robra-Bissantz, University of Erlangen-Nuremberg, Germany \\ Bernd Weiser (E-mail: weiser@ forwin.de), University of Erlangen-Nuremberg, Germany
}

\begin{abstract}
By addressing customers individually and taking over selected tasks, push concepts allow suppliers to play a more active role in e-commerce and to improve their customer relationship management (CRM). An overview on nature, concepts and technical implementations of push concepts is given. The main characteristics of CRM and opportunities offered by concepts of mass customization are described. Special attention is paid to push concepts on relationship level, as this is particularly relevant for CRM. Different approaches to predict future needs of the customer and to derive individual offers are introduced. In the proposed concept, actively addressing customers leads to differentiation strategies at moderate costs. The advantages of integrating push concepts into CRM are summarized and classified in a final conclusion.
\end{abstract}

\section{Introduction}

E-Commerce using the Internet is mainly based on pull concepts with the customer being the active "pulling" partner who initiates and controls the transactions. He/she pulls information from the network, asks for offers, specifies his/her wishes, compares different companies and finally sends his/her order. The supplier rather reacts than he is able to act himself. He is faced with multiple "stoppages" during the transaction where he has to wait for customer actions. Usually it cannot be foreseen if or when the customer will make contact again.

Proactive approaches for the supplier are introduced to overcome this uncomfortable situation. These approaches are often called push concepts. In this case, the supplier takes the initiative and control during interactions with the customer.

\section{Push Concepts in Customer Oriented Strategies}

The crucial idea of push concepts is, that the supplier takes over functions from the buyer or at least triggers the buyer to take further steps in the buying process. Additionally there are two more characteristics of push concepts. All actions and triggers have to be individualized for one special customer, which e.g. excludes e-mail messages being sent to several recipients ("spam"). We assume an existing electronic relationship between a customer and a supplier (see Figure 1).

An integrative application of push concepts to mass customization in CRM seems to be promising because of multiple interdependencies between the concepts, e.g.:

- Technologies of CRM that enable the collection and processing of customer information, namely database marketing or data mining systems, build up the basis for opportunities to push.

- The "individuality" of push activities requires that the offers can be personalized. The prerequisite for individual offers is, that the product, the service or additional services can be configured, e. g. by modularization. Therefore it seems obvious to combine push concepts with concepts of mass customization. 


\section{Figure 1 : Characteristics of Push Concepts}

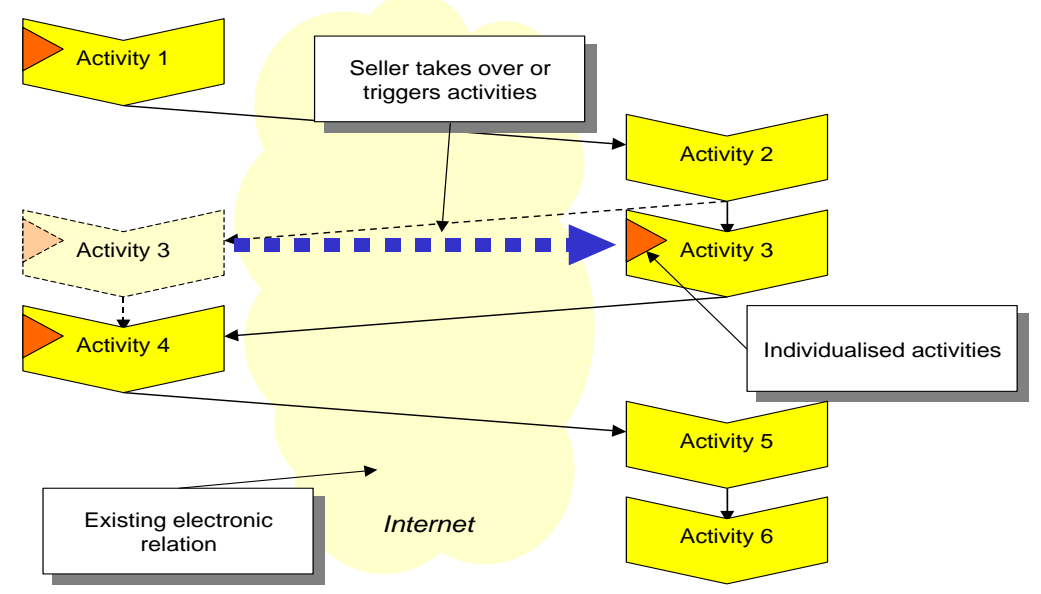

\section{Levels of Push Activities}

A conceptual meta-framework helps to classify push opportunities and to describe starting-points for Push Activities on several levels of the customer relationship [Robra-Bissantz, Weiser, 2001]. It comprises of three levels (see Figure 2):

\subsection{Interaction Level}

Here an interaction consists of a single, synchronous communication between buyer and supplier respectively their IT systems. If the buyer is about to abort an interaction without meeting the interaction's goal (e.g. completing an online order form and sending it to the supplier), a push opportunity arises. The supplier has to recognise the buyer's intention in time and react appropriate to continue the interaction.

\subsection{Transaction Level}

An economic transaction consists basically of the information phase, negotiation phase and settlement phase [e. g. Gebauer 1996, pp.15]. These phases may as well be divided into a number of smaller sub-phases [Ferstl, Sinz 2001, pp.189]. If a phase is completed and the buyer has to initiate the next transaction phase, the application of push principles can consist either in re-addressing the customer to motivate him to continue or, in more sophisticated concepts in the supplier taking over the execution of a formerly buyer-dominated action.

\subsection{Relationship Level}

On this level push approaches do not aim at the completion of already initiated transactions but at the commencement of new transactions in the relationship life cycle [Plinke 1989, pp. 307]. This can be realized by the automated perception of promising situations, followed by the generation of individual offers covering the expected needs of the customer. 


\section{Figure 2 : Levels of Push Concepts}

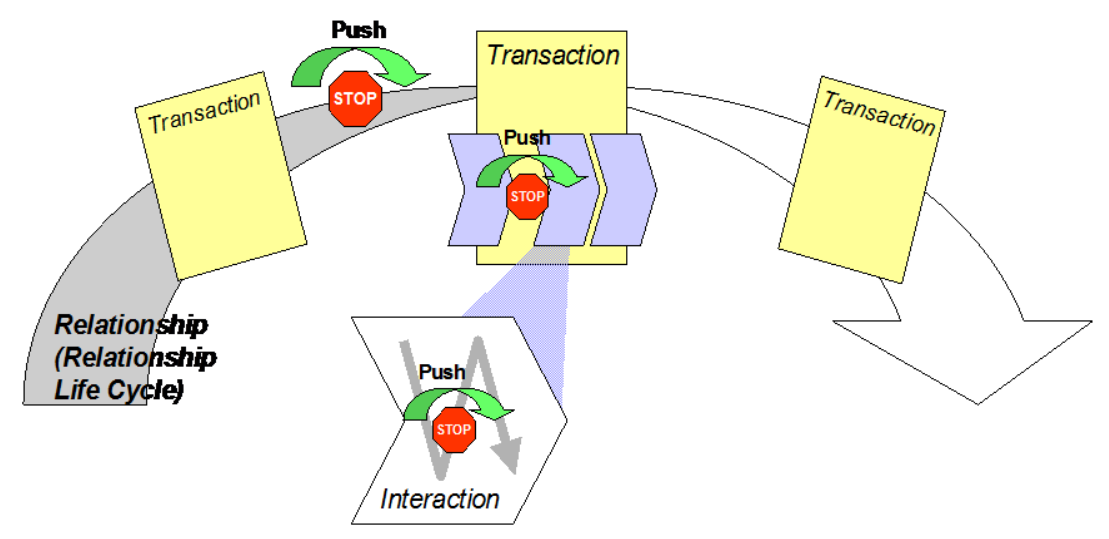

\section{Implementation of Push Concepts}

A comprehensive implementation of Push Concepts requires developments in mainly three fields [RobraBissantz, Weiser, 2001] as pictured in Figure 3.

\subsection{Interaction Strategies}

To apply push principles successfully the company has to define a push plan for customers or customer groups and a push flow through single transactions in order to connect conceivable push opportunities with appropriate push activities. With an additional checklist of possible stoppages during interactions the company can recognise push opportunities on all push levels. Push plans and push flows can be defined by customising general strategies or by applying basic theoretical models for strategy definition.

\subsection{Interaction Modules}

Interaction modules are reusable software components supporting specified types of interaction in push activities. They combine conceptual interaction patterns with supporting technical solutions, e.g. pop-up-windows presenting additional payment information if the customer hesitates when choosing a payment option. The application of predefined interaction modules depends on the specific push opportunity. General push opportunities are customer functions that can be adopted or triggered by the seller.

\subsection{Interaction Control}

On all push levels control modules observe interactions and transactions with the customer and collect information that is stored in a customer record. If a push opportunity as defined in the push strategies is detected the control modules trigger the appropriate interaction modules. During an interaction (e.g. a web site visit), a so called push spy monitors all customer activity as a background process. It recognizes stoppages, e. g. if a customer tries to leave the web site after having searched in several categories and triggers an interaction module, e. g. a call-mebutton to become visible. On transaction level, the so called push flow manager supervises the ongoing order process. If significant delays are observed, it analyzes possible reasons and calls interaction modules, according to the special situation and transaction phase, to make the buyer continue the process. The push planner tries to find opportunities to initiate new transactions according to the push plan for the particular customer. 


\section{Figure 3: Fields of development of Push Concepts}

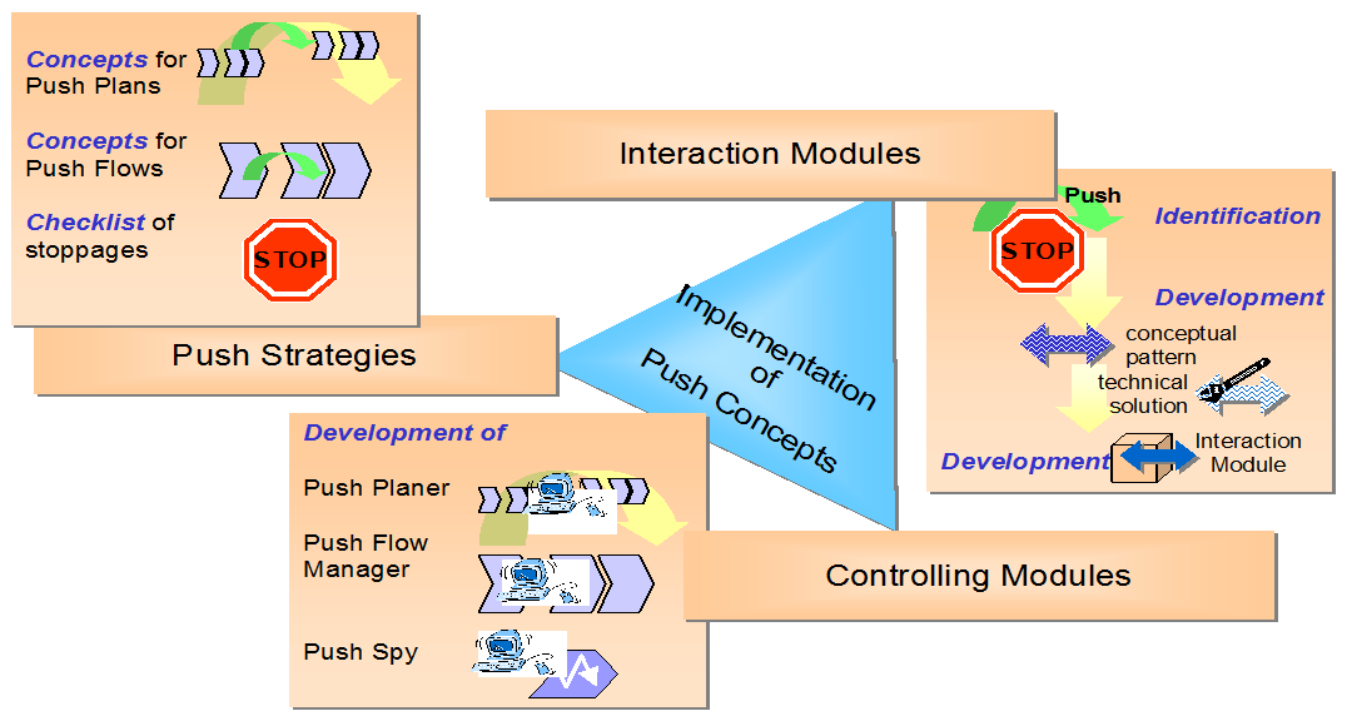

\section{CRM and Mass Customization}

As comprehensive concept for customer oriented strategies in e-commerce customer relationship management orientates all companies' activities to longer lasting customer relationships with current and prospective customers in order to enhance the companies' success [Hildebrand 1997, Link, Hildebrand 1997, Weiber, Weber 2000]. The leading concept of CRM is an individualization of communication as well as of products and services in the whole customer life cycle.

Mass customization [e. g. Choi, Stahl, Winston 1997; Kotler 1989] aims at a large number of potential customers and offers them individualized products (differentiation option) at a price that roughly corresponds to the price of a mass product (cost option). Tailored products for particular customers can only be produced at comparatively low cost if the whole production process is transformed, which includes for example a change of the order in which parts are assembled. Mass customization can improve CRM concepts [Piller 2000]. The differentiation option, where customers tailor their products themselves leads to additional knowledge about them, compared to one-to-one-marketing strategies. The relationship between company and customer becomes more intense with each contact, so that in repeat contacts individualisation information can be raised more easily (learning relationship) [Peppers, Rogers 1997, pp. 168-194]. Aggregation and comparison of information from different customers allow a better service for new customers (via profiling) and product modifications according to customers' taste. Even more important for successful CRM is the cost option of mass customization. Producing the product or the service after selling it, leads to smaller risks than the traditional variant production and to smaller storekeeping costs. Production costs can be kept low with the new concepts for manufacturing of high market potential products with little internal and great external variety [Piller 1999, pp. 222f.]. For relationships with single customers mass customization leads to economies of scale (concerning the sales potential of one customer), economies of scope (concerning the range of products that can be sold to one customer) and economies of learning (by applying the concept of the learning relationship) [Piller 1998, pp. 171f.]. 


\section{Push Concepts for Proactive CRM}

Push concepts for CRM and mass customization can be found on the relationship level. In order to discover functions that can be adopted by the supplier, the customer's processes and activities are analyzed. On relationship level we find four aspects that can explain future needs:

1. Identity of the customer (structure and positioning of business customers, personality and preferences of private customers)

2. Position of the customer in his life cycle (education and marital status of private customers, developmental stage of companies)

3. Relationship to the supplier (position in a Relationship Life Cycle, e. g. new/regular customer)

4. Processes of the customer (business processes or processes in private life)

A seller can adopt the function of identification and specification of a need as well as a first configuration of a product, if he knows the customer's situation, preferences and development. He can basically find opportunities for offering new products or special offers to customers according to their profile or their buying history. New specific push concepts are based on a dynamic perspective by the use of the customer and relationship life cycle.

In general there are different options for the design of push plans on relationship level, that can be described by different models to discover future needs, different time perspectives and an optional inclusion of profiling information as depicted in Table 1.

Table 1: Options for Push Plans

\begin{tabular}{|l|l|l|l|l|}
\hline model & identity & $\begin{array}{l}\text { customer } \\
\text { life cycle }\end{array}$ & $\begin{array}{l}\text { relation- } \\
\text { ship life } \\
\text { cycle }\end{array}$ & process \\
\hline $\begin{array}{l}\text { time } \\
\text { perspective }\end{array}$ & static & dynamic \\
\hline $\begin{array}{l}\text { information } \\
\text { basis }\end{array}$ & one customer & customer group \\
\hline
\end{tabular}

For a supplier, who mainly sells goods and services for single or seldom occurring needs, it is important to predict the development of the customer in order to find out the chances when a new or different need, that he can satisfy, appears. By observation of the customer life cycle and anticipation of it's future stages the seller can discover these potentials e. g. for cross selling. Together with a consideration of the relationship life cycle and the collection of information about the customer's preferences he is able to generate an individual offer for a product or a service. The push plan suggested for this kind of push approach is the life cycle anticipation. It can be described as depicted in Table 2.

Table 2: Description of Life Cycle Anticipation

\begin{tabular}{|l|l|l|l|l|}
\hline model & identity & $\begin{array}{l}\text { customer } \\
\text { life cycle }\end{array}$ & $\begin{array}{l}\text { relation- } \\
\text { ship life } \\
\text { cycle }\end{array}$ & process \\
\hline $\begin{array}{l}\text { time } \\
\text { perspective }\end{array}$ & static & dynamic \\
\hline $\begin{array}{l}\text { information } \\
\text { basis }\end{array}$ & one customer & customer group \\
\hline
\end{tabular}


Suppliers that sell expendable goods have to emphasise concepts that intensify their relationship to the customer. The buying history of the customer has to be analysed and orders have to be compared with a future situation, where the supplier satisfies all possible needs of the customer. This requires an analysis of the relationship life cycle which, under consideration of the customer's processes and identity, leads to offers for additional products. For supplemental prospective offers the customer life cycle should be applied and matched with the buying history, to predict his development. The basic concept in this situation is called the expanding shopping list (see Table 3).

Table 3: Description of Expanding Shopping List

\begin{tabular}{|l|l|l|l|l|}
\hline model & identity & $\begin{array}{l}\text { customer } \\
\text { life cycle }\end{array}$ & $\begin{array}{l}\text { relation- } \\
\text { ship } \\
\text { life cycle }\end{array}$ & process \\
\hline $\begin{array}{l}\text { time } \\
\text { perspective }\end{array}$ & static & dynamic \\
\hline $\begin{array}{l}\text { information } \\
\text { basis }\end{array}$ & one customer & customer group \\
\hline
\end{tabular}

\section{Conclusion}

The application of proactive push concepts on relationship level to CRM offers three approaches to improve efficiency and effectiveness in relationships with customers in electronic commerce:

\subsection{Supplier Activity}

The most interesting aspect of an addition of push principles to CRM and mass customization is, that the seller assumes the active role in e-commerce. He doesn't wait for the customer to come or proceed in his transaction to supply him with better, individualised products or services but he decides when to approach him. The basic concept for this activity approach is the acquisition of customer functions. Relevant functions are the identification and specification of prospective customer needs as well as an individualization of the product. Specialized concepts for anticipating future needs are push plans derived from life cycle anticipation and expanding shopping list.

\subsection{Differentiation Option}

A competitive advantage lies in better composition of products and services. Push concepts that offer a first configuration that can subsequently be customized in a kind of top down manner are in many cases a better and more convenient starting basis than leaving the whole customization process to the customer. The primary proposal for the product will become better by-and-by, for one particular customer caused by the learning relationship. Across many customers, case based reasoning components can learn from each customization, so that the system can offer improved first configurations.

\subsection{Cost Option}

Push concepts are designed to offer differentiation advantages and the opportunities of active customer address with simultaneous consideration of their costs. Examples for standardisation are the push strategies and the software components:

- $\quad$ After a first creation of push plans the company can adopt them standardized and possibly improved for all following customers.

- Interaction modules are standardized and reusable with regard to the conceptual patterns and technical implementation. 
The building block approach of interaction modules enables a general development of an expandable library and a versatile application on interaction, transaction and relationship level as well as in all branches and ecommerce solutions.

\section{References}

1. Choi, S.-Y., Stahl, D. O., Whinston, A. B., The economics of electronic commerce, Indianapolis 1997.

2. $\quad$ Ferstl, O. K., Sinz, Elmar J., Grundlagen der Wirtschaftsinformatik, Band 1, München 2001.

3. Gebauer, J., Informationstechnische Unterstützung von Transaktionen: Eine Analyse aus ökonomischer Sicht, Wiesbaden 1996.

4. $\quad$ Hildebrand, V., Individualisierung als strategische Option der Marktbearbeitung, Wiesbaden 1997.

5. Kotler, P., "From mass marketing to mass customization", in: Planning Reveiw 17, 1989, 5, pp. 191-234.

6. $\quad$ Link, J., Hildebrand, V., "Grundlagen des Database Marketing”, in: Link, J.; Brändli, D.; Schleuning, Ch.; Kehl, R. E. (Hrsg.), Handbuch Database Marketing, Ettlingen 1997, pp. 16-36.

7. $\quad$ Peppers, D., Rogers, M., Enterprise one to one, New York 1997.

8. $\quad$ Piller, F., Kundenindividuelle Massenproduktion, München 1998.

9. Piller, F., Mass Customization als wettbewerbsstrategisches Modell industrieller Wertschöpfung in der Informationsgesellschaft, Würzburg 1999.

10. Piller, F., "Mass Customization-Konzepte im Electronic Business", in: Weiber, R. (ed.), Handbuch Electronic Business, Wiesbaden 2000, pp. 359-382.

11. Plinke, W., "Die Geschäftsbeziehung als Investition”, in: Specht, G., Silberer, G., Engelhardt, W. H. (ed.), Marketing-Schnittstellen - Herausforderungen für das Management, Stuttgart 1989, pp. 305-325.

12. Robra-Bissantz, S., Weiser, B., Ein Meta-Framework zur Identifizierung und Beschreibung von PushMöglichkeiten im E-Commerce, FORWIN-Bericht, to appear 2001.

13. Weiber, R.; Weber, M. R., "Customer Lifetime Value als Entscheidungsgröße im CRM", in: Weiber, R. (ed.), Handbuch Electronic Business, Wiesbaden 2000, pp. 473-504. 
Notes 